Trakya Eğitim Dergisi

Cilt 10, Sayı 3

Eylül 2020, 744-763

Gelis Tarihi: 17.09.2019.

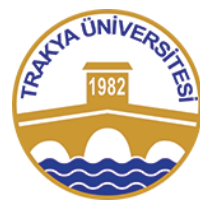

ISSN: $2630-6301$

Doi: $10.24315 /$ tred.621006

Araştırma Makalesi

Research Article
Trakya Journal of Education

Volume 10, Issue 3

September 2020, 744-763

Yayına Kabul Tarihi:21.05.2020

\title{
Popüler Kültür Unsuru Olarak Tarihi Dizilere İlişkin Sosyal Bilgiler Öğretmenlerinin Görüşleri
}

\section{Opinions of Social Studies Teachers on Historical Sequences As An Element of Popular Culture}

\author{
Melike FAIZ ${ }^{1}$, Emine KARASU AVCI ${ }^{2}$
}

ÖZ: Popüler kültür, iletişim araçlarını ve teknolojiyi kontrol edenler tarafindan üretilen ve geniş halk kitlelerini etkisi altına alan bir kültürdür. Popüler kültürün yayılıp genişlemesinde televizyonun önemli bir yeri vardır. Tarihi diziler televizyonun önemli parçalarından biridir. Bu diziler tarihi olay ve olguları konu alan ve kitleleri etkileyen görsel yapıtlardır. Bu araştırmanın amacı, popüler kültür unsuru olarak tarihi dizilere ilişkin Sosyal Bilgiler öğretmenlerinin görüşlerini ortaya çıkarmaktır. Araştırma durum çalışmasına uygun olarak tasarlanmıştır. Araştırmanın çalışma grubunu 65 öğretmen oluşturmaktadır. Araştırmada veri toplama aracı olarak yarı yapılandırılmış görüşme formu kullanılmıştır. Elde edilen veriler içerik analiziyle çözümlenmiştir. Öğretmenler tarihi dizilerden Diriliş Ertuğrul, Vatanım Sensin, Payitaht Abdülhamit, Mehmetçik Kut'ül Amare, Vikingler ve Aliya dizilerini izlediklerini belirtmişlerdir. Öğretmenler tarihi dizi karakterlerinden etkilendiklerini ve tarihi dizilerin insanların tarihe ilgisini artırdığını ve tarih hakkında bilgi sahibi yaptığını düşünmektedirler. Ayrıca öğretmenler tarihi dizilerle tarihi gerçekler arasında farklar olduğu, kadın-erkek ilişkilerinin ön planda tutulduğu ve şiddet sahnelerinin bulunduğu gibi olumsuz görüşler de belirtmişlerdir.

Anahtar sözcükler: Popüler kültür, tarihi dizi, Sosyal Bilgiler, ögretmen.

Bu makaleye atıf vermek için:

Faiz, M. \& Karasu-Avc1, E. (2020). Popüler kültür unsuru olarak tarihi dizilere ilişkin sosyal bilgiler öğretmenlerinin görüşleri. Trakya Eğitim Dergisi, 10(3), 744-763.

Cite this article as:

Faiz, M. \& Karasu-Avc1, E. (2020). Opinions of social studies teachers on historical sequences as an element of popular culture. Trakya Journal of Education, 10(3), 744-763.

\section{EXTENDED ABSTRACT}

\section{Introduction}

Popular culture is the culture produced by those who control the means of communication and technology and which influences the wider public. This culture was produced by those who controlled the mass media and technology and presented for the consumption of individuals. Thus, popular culture has become both an economic activity and an effective tool on the public (Yaylagül, 2004). In this respect, it can be said that popular culture is the culture created by consumerism. Television has an important place in the spread and expansion of popular culture. Television is a mass media affect the lives of every human being. Television, on the one hand, represents the time that flows, and on the other hand it historicalizes this time. By presenting historical documents to humanity, he dominates the memories. It can be said that with the messages emitted by television, it shapes the views of large

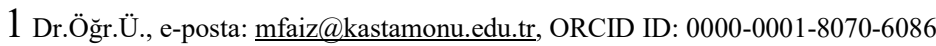

2 Dr.Öğ.Ü., e-posta: eavci@kastamonu.edu.tr, ORCID ID: 0000-0002-3135-2557 
masses of people and directs daily life practices, individual behaviors and social relations (Yücel, 2019). Historical series is one of the important programs of television. These series are visual works that deal with historical characters, events and phenomena and affect the masses. These series are important in understanding and teaching history (Aktekin \& Çoban, 2011). Since they have a structure that visualizes history, it is effective in establishing strong ties to history. Through the historical series, the consciousness of history and history can be gained.

Historical series, which is the product of popular culture, is also important for the field of Social Studies education. Analyzing historical narratives, establishing historical empathy, perceiving time and chronology, perceiving change and continuity, recognizing cultural elements and contributing to historical knowledge. Historical series is a more successful source in transferring a historical event than sources such as books, magazines and paintings (Rosenstone, 2001; Öztaş, Anıl \& Kılıç, 2013). In this respect, historical series will contribute to the achievement of the objectives of the Social Studies course. With historical series, an abstract field such as history, which is one of the disciplines of Social Studies course, will be made concrete. Historical sequences make history learning fun. Watching these series by social studies teachers; it will be effective in contributing to the course, presenting examples in the lesson and guiding the students towards the series to be watched.

\section{Method}

The aim of this study is to determine the views of Social Studies teachers about historical series as a popular culture element. This study was designed with a case study pattern. The study group consists of 65 Social Studies teachers who watch historical series. Therefore, the criterion sample which is one of the purposeful sample types was determined as sampling. As a data collection tool, semi-structured interview form prepared by the researchers was used. Accordingly, the research problem of the study: What are the views of Social Studies teachers about historical series, a popular cultural product?

Sub problems:

1. What are the current historical series that teachers watch?

2. What are the historical series that teachers watched in the past?

3. What are the topics of current historical series that teachers watch?

4. Which characters were the teachers affected by in the historical series? Why is that?

5. According to the teachers, is there any difference between historical series and real history?

6 . How do the teachers give examples in their lessons on historical series?

7. What are the effects of historical series on social life according to teachers?

8. According to the teachers, what are the situations that disturb them in the historical series?

The data obtained from the research were analyzed through content analysis. Content analysis; editing, classification, comparison and interpretation of these results based on the analysis of the text (Cohen, Manion \& Morrison, 2007). The validity of the study was provided by presenting the data of the opinions of the Social Studies teachers in tables and by providing direct quotations. It is also clearly stated in the analysis process. In the research, reliability was tried to be achieved by analyst triangulation. In this research, the researchers analyzed and coded the data independently. Before the data were transferred to the table, the codings were compared and compared. Different points were discussed and concluded. Miles \& Huberman (1994) formulated by the percentage of reconciliation (\% of consensus $=$ Consensus $/($ Consensus + Disagreement $) \times 100$ ratio is recommended to be close to $80 \%$. In this research, the categories made by the researchers were compared and the same categories as consensus and different categories were determined as disagreement and reliability was calculated for each question, and the percentage of reconciliation was calculated as $159 / 159+10 \times 100=94$.

\section{Discussion and Conclusion}

According to the results obtained from the study, teachers stated that they watched the historical series Diriliş Ertuğrul, Vatanım Sensin, Payitaht Abdülhamit, Mehmetçik Kut'ül Amare, Vikings and Alija. Teachers state that they are influenced by historical series characters. They also think that historical series, increase people's interest in history and make them aware of history. However, the teachers stated that there are differences between historical series and historical realities, the relationship between men and women is in the foreground and there are too many scenes of violence. 
Some research results supporting the findings have been reached in the literature. Öztaş, et al., (2013) found that historical series increased interest in history. In the study of Aktekin \& Çoban (2011), teachers stated that historical series increased their students' interest in history lesson. Şahin (2019) concluded that the consciousness of history of prospective teachers who watch historical series strengthens. In their study, Ocak \& Selimoğlu (2016) state that characters and events are removed from reality in historical series. Erman (2016) states that historical series are shaped in line with the policy advocated by the period and that the masses are intended to be directed. Love relations, tension, conflict and violence are frequently included in the establishment of the plot and the continuation of the series (Geçer, 2015). Obscene scenes shown in historical series and scenes containing violence (fight, war, insult, etc.) damage social values (Kaya \& Çengelci, 2011). Therefore, it can be said that the findings obtained from this study are similar to the results of the studies in the literature.

\section{GíRiş}

Popüler kültür, kitleleri farkında olmadan etkisi altına alabilen ve kendine bağımlı hale getirebilen, gelip-geçici gündelik bir hayat kültürü olarak ifade edilmektedir. Gündelik bir tüketim kültürü olmakla birlikte kitleleri eğlendirmekte ve onlar üzerinde yönlendirici etkiye sahip olabilmektedir. Popüler kültür ve popüler kültür ürünleriyle birlikte kitleler standart bir tüketim kalıbına sokularak aynı ürünleri tüketmekte ve aynı alışkanlıkları sergilemektedirler. Popüler kültürün kitleler üzerindeki bu etkisi kitleleri hayata karşı daha duyarsız hale getirmekte ve topluma karş1 yabancılaştırmaktadır.

20. yüzyıl öncesinde demokrasinin ve iletişim araçlarının yeterince gelişmemiş olması, iktidarın ve iletişim araçlarının belli kişi ya da grupların elinde bulunması popüler kültürün yaygın etkisini sınırlandırmaktaydı. Ancak süregelen zamanla birlikte siyasi ve ekonomik şartların değişmesi yönetim kadroları gibi iletişim kanallarına sahip kadroların da el değiştirmesine neden olmuştur (AltınbaşSarı̈ül, 2017).

Başlangıçta halk tarafından üretilen kültürü ifade etmek için kullanılan popüler kültür, 20.yüzyılda teknolojinin hızla gelişmesiyle birlikte medya tarafından üretilen ve medyanın etkisiyle kitleleri etkisi altına alabilen kültür olarak kullanılmaya başlanmıştır. Bu kültür, kitle iletişim araçlarını ve teknolojisini kontrol edenler tarafından üretilmiş ve bireylerin tüketimleri için sunulmuştur. Böylece popüler kültür hem ekonomik bir etkinlik hem de kitleler üzerinde etkili olan bir araç haline gelmiştir (Yaylagül, 2004). Bu yönüyle popüler kültürün, tüketiciliğin yarattığı kültür olduğu da söylenebilir. Bu kültürde bireyler birer tüketici olarak konumlandırılmaktadır (Cengiz, 2010). Bir başka görüşe göre de popüler kültür; opera, tiyatro, klasik müzik ve klasik edebiyatın karşıtı olarak tanımlanmaktadır. Halkın sevdiğinden ziyade kabul ettirilmeye çalışılan kültürdür. Küreselleşen dünyada yeni pazarlar yaratmak amacıyla ortaya atılan bir olgudur. Bu olgu, tüm insanlığın kendi kültürünü unutmalarını, kendilerine sunulanı beğenmelerini öngörür. Tüm dünyada tek ve ortak zevkler ve değerler oluşturulmasını temel alan popüler kültür maalesef milli değerlerin göz ardı edilerek unutulmasına neden olmaktadır (Sakallı, 2014).

Popüler kültürün bir amacı da insanlara hayata başkasının gözüyle bakmayı ve yaşamayı öğretmektir. Böylece insanlar kendilerinden uzaklaştırılıp, kendi aidiyetine ve özüne yabancılaştırılmaktır (Coşgun, 2012). Tüm dünyada egemen olmayı hedefleyen popüler kültür televizyondan sinemaya, kitaptan müziğe, giyimden gıdaya kadar yaşamın her alanını etkilemektedir. Bu kültürün ürünü olan tüketim malları yaş, cinsiyet, eğitim, meslek ve sosyal sınıf ayrımı olmaksızın büyük kitleler tarafindan kabul edilmektedir (Kızıldağ, 2001; Erdoğan ve Alemdar, 2005).

Günümüz toplumları için medya, etkili sosyal kurumlardan biri haline gelmiştir. Medyanın ürettiği sanal dünyada bireyler yeni kültür biçimleriyle karşılaşmakta ve geleneğin kalıplarını kırmaktadırlar (Güllüoğlu, 2012). Televizyon, radyo, internet, cep telefonu, bilgisayar gibi çeşitli kitle iletişim alanındaki teknolojik gelişmeler bireylerin hayatına girmekte ve vazgeçilmezi haline gelmektedir. Tezcan'a (2000) göre medya, popüler kültürün yayılıp genişlemesini sağlayan önemli iletişim aracıdır. İletişim araçları, insanların ne yiyeceği ve nasıl giyineceği gibi konularda belirleyici olmaktadır (Kızıldağ, 2001). Bireylerin yaşadığı bu yeni durum popüler kültür olarak değerlendirilmektedir. Popüler kültür varlığını kitle iletişim araçları yoluyla yaygınlaştırmakta ve kitlelere seslenmektedir. Kitle iletişim araçları içinde görüntü ve ses yoluyla geniş yığınlara ulaşabilen televizyonun ayrı bir yeri bulunur (Güllüoğlu, 2012). Giddens (2005) televizyonun, her insanın hayatını 
etkileyen kitle iletişim aracı olduğunu belirtir. Televizyon bir taraftan akıp giden zamanı temsil ederken bir taraftan da bu zamanı tarihselleştirmektedir. İnsanlığa tarihsel belgeler sunarak belleklere hâkim olmaktadır. Örneğin 12 Eylül 1980 darbesi ile ilgili binlerce sayfalık kayıt bulunmaktadır. Ancak bu kayıtların hiç biri uçakların İkiz Kulelere dalışını gösteren görüntüler kadar insanlar üzerinde kalıcılık sağlayamamıştır. Irak'ta Saddam'ın devrilişi, Japonya'daki tsunami felaketi, Libya'da Kaddafi'nin katli gibi olayların televizyonlar aracılığıyla tüm dünya ile paylaşılması televizyonun insanlar üzerinde algı oluşumunu sağlama rolünü ortaya koymaktadır (Bilis, 2013). Dolayısıyla televizyonun yaydığı mesajlar ile geniş insan kitlelerinin görüşlerini biçimlendirdiği, günlük yaşam pratiklerini, bireysel davranışları ve sosyal ilişkileri yönlendirdiği söylenebilir (Yücel, 2019).

Kendine özgü ileti sistemleri ve sembolleri bulunan televizyon, bu sistem ve sembolleri değişik programlar yoluyla sergilemektedir. Bu programlardan biri de dizilerdir. Dizilerin formatlarının televizyonun yapısına çok uygun olması, izleyicide algılamayı ve bağlantı kurmayı kolaylaştırmaktadır. $\mathrm{Bu}$ durum dizilerin gündelik yaşamın ayrılmaz bir parçası haline gelmesini sağlamıştır. Bu nedenle dizilerin toplumsal yapıyı yansıtması ve şekillendirmesi kaçınılmazdır (Yaktıl-Oğuz, 2005). Özellikle televizyon dizilerinin toplum üzerinde kayda değer etkisi olduğu görülmektedir (Gezici ve Demir, 2018). Diziler izleyicilerin zihinlerine çeşitli imajlar, görüşler ve algılar gönderirler. Bu sayede insan davranışlarını biçimlendirici ve yönlendirici bir rol oynarlar (Altınbaş-Sarıgül, 2017).

Tarihi diziler, tarihi konu alan ve toplum tarafindan her zaman ilgi gören görsel yapıtlar olarak tanımlanabilir. Bu diziler, tarihi anlama ve öğretme konusunda önemlidirler (Aktekin ve Çoban, 2011). Tarihi diziler tarihi görselleştiren bir yapıya sahip olduğu için tarihe yönelik güçlü bağlar kurulmasında etkilidir (Öztaş, vd., 2013). Dizilerin görsel ve işitsel olması ile duygulara hitap etmesi insanlar üzerinde etkili olmasını sağlamaktadır (Kaya ve Günal, 2015; Ocak ve Selimoğlu, 2016). Tarihi diziler ele aldığı dönemin sosyo-ekonomik, kültürel, psikolojik ve sosyolojik süreçlerini bir bütün olarak sergilemektedir. Bu yönüyle tarihi dizilerin sadece olay ve karakterlerle sınırlı kalmadığı da söylenebilir (Öztaş, 2007). Dolayısıyla tarihi diziler yoluyla toplumu ayakta tutan tarih ve tarih bilinci kazandırılabilir (Kalçık, 2019).

Popüler kültürün ürünü olan tarihi diziler Sosyal Bilgiler eğitimi alanı için de önem taşımaktadır. Tarihsel anlatıları analiz etme, tarihsel empati kurma, zaman ve kronolojiyi algılama, değişim ve sürekliliği algılama, kültürel unsurları fark etme ve tarihsel bilgi birikimine katkı sağlamaktadır. Tarihi diziler, bir tarihi olayı aktarmada kitap, dergi, resim gibi kaynaklardan daha başarılı bir kaynaktır (Rosenstone, 2001; Öztaş, Anıl ve Kılıç, 2013). Bu yönüyle tarihi diziler Sosyal Bilgiler dersinin kazanımlarının hedeflerine ulaşmasına katkı sağlayacaktır. Tarihi diziler ile Sosyal Bilgiler dersinin disiplinlerinden biri olan tarih gibi soyut bir alan somut hale getirilecektir. Tarih öğrenmeyi eğlenceli hale getiren tarihi dizilerin Sosyal Bilgiler öğretmenleri tarafından da takip edilmesi derse katk1 sağlama, örnekler sunma ve öğrencileri izlenecek diziler konusunda doğru yönlendirmede etkili olacaktır.

Literatürde tarihi dizilerle ilgili çeşitli çalışmaların yapıldığı görülmektedir. Bu çalışmalarda genellikle tarih derslerinde tarihi dizilerin ve filmlerin kullanılmasına ilişkin çalışmalar (Aktekin ve Çoban, 2011; Kaya ve Günal, 2015; Ocak ve Selimoğlu, 2016; Özmen, Er ve Ünal, 2014; Öztaş, vd., 2013; Öztaş, 2015) yapılmıştır. Bununla birlikte tarihi dizilerle yaşam boyu öğrenme algısı (Kalçık, 2017; Şahin, 2019); tarihi dizilerin ve filmlerin Sosyal Bilgiler dersine yansımaları (Gezici ve Demir, 2018) konularının da çalışıldığ 1 görülmektedir. Yapılan bu çalışmalarda tarihi dizilere yönelik öğretmen, öğrenci ve öğretmen adayı görüşlerine başvurulmuştur. Bu çalışmalar daha çok tarih öğretimine yöneliktir. Gezici ve Demir'in (2018) çalışması dışında tarihi dizi ve Sosyal Bilgiler ilişkisini ele alan başka herhangi bir çalışmaya rastlanılmamaktadır. Turner (1979) popüler kültürün derslerde kullanılması gerektiğini belirtir. O’na göre popüler kültür, öncelikle bireyin kişisel ve sosyal gelişimi ve kişisel alışkanlıkları, kendi kavramları ve hayalleri ile ilgilidir. Öğrenciler, popüler kültür aracılığı ile daha detaylı bilgi öğrenmekte ve bunları sorgulamaktadırlar. Çatışma ve görüş ayrılıklarını kendi bakış açısıyla değerlendirebilir ve sonuca ulaşabilirler. Popüler kültür materyalleri de genellikle ucuz ve kolayca ulaşılabilirdir. Bu nedenle öğrencilerin günlük hayatlarının birer parçasıdırlar. Popüler kültür öğrencilerin ilgi ve meraklarını uyandırmada ve diğer kültürler hakkında bilgi edinmesi açısından oldukça önemlidir.

Tarihi dizilerin de bir popüler kültür aracı olduğu düşünüldüğünde, eğitim ortamlarının uygulayıcısı olan Sosyal Bilgiler öğretmenlerinin tarihi dizilere bakış açıları bu dizilerden örnek vermeleri ya da derslere katkı sağlamaları açısından önem taşımaktadır. Bu araştırmada Sosyal Bilgiler 
öğretmenlerinin popüler kültürün unsuru olan tarihi dizilere ilişkin görüşlerinin ortaya çıarılması amaçlanmaktadır. Bu doğrultuda çalışmanın araştırma problemi: nelerdir?

Sosyal Bilgiler öğretmenlerinin bir popüler kültür ürünü olan tarihi dizilere yönelik görüşleri
Alt problemler:
1. Öğretmenlerin izledikleri güncel tarihi diziler nelerdir?
2. Öğretmenlerin geçmişte izledikleri tarihi diziler nelerdir?
3. Öğretmenlerin izledikleri güncel tarihi dizilerin konuları nelerdir?
4. Öğretmenler tarihi dizilerdeki hangi karakterlerden etkilenmişlerdir? Neden?
5. Öğretmenlere göre tarihi dizilerle gerçek tarih arasında fark var mıdır?
6. Öğretmenler tarihi dizilerle ilgili derslerinde nasıl örnekler veriyorlar?
7. Öğretmenlere göre tarihi dizilerin toplumsal yaşama etkileri nelerdir?
8. Öğretmenlere göre tarihi dizilerde kendilerini rahatsız eden durumları nelerdir?

\section{YÖNTEM}

\section{Araştırmanın Modeli}

$\mathrm{Bu}$ çalışma, durum çalışması deseniyle tasarlanmıştır. Durum çalışmaları, bireysel, grup, örgütsel, sosyal, politik ve ilgili fenomenler hakkında bilgilerimize katkıda bulunmak için bir çok durumda kullanılır. Ayrıca çağdaş bir fenomeni gerçek yaşam bağlamında araştıran ampirik bir soruşturma olarak; fenomen ve bağlam arasındaki sınırlar açıkça belli olmadığında ve birden fazla kanıt kaynağının kullanıldığı çalışmalarda kullanılmaktadır. Bir çok durumda kullanılan bu tekniğin ayırt edici özelliği sosyal olayları anlama arzusundan kaynaklanmaktadır (Yin, 1984). Çalışma durum çalışması tekniklerinden iç içe geçmiş tek durum desenine göre yapılmıştır. Bu türde tek bir durum içinde çoğu kez birden fazla alt tabaka ya da birim olur ve bu birimler analize tabi tutulur. İlgili durumu, bütüncül ve tek bir ünite olarak ele alınması veya bir durum içinde olabilecekken birden fazla alt birimlere yönelmesi söz konusudur (Yin, 1984). Popüler kültür bir bütün ve onun içerisinde olan tarihi diziler alt birim olarak düşünüldüğünden bu çalışmanın bu desene uygun olduğu düşünülmüştür.

\section{Çalışma Grubu}

Bu araştırmanın çalışma grubunu, 2018-2019 eğitim-öğretim yılı bahar yarıy1lında Milli Eğitim Bakanlığı'na bağlı okullarda çalışan ve araştırmaya gönüllü olarak katılmayı kabul eden 65 Sosyal Bilgiler öğretmeni oluşturmaktadır. Bu araştırmada amaçlı örnekleme türlerinden ölçüt örnekleme yöntemi kullanılmıştır. Amaçlı örnekleme, zengin bilgiye sahip olduğu düşünülen durumların derinlemesine çalışılmasına olanak veren örnekleme türüdür (Patton, 1997). Ölçüt örnekleme ise, araştırmacı ya da araştırmacılar tarafından önceden belirlenmiş belli ölçütleri sağlayan bütün durumların çalışılmasına imkân veren gruplardan meydana gelir (Patton, 1997; Yıldırım ve Şimşek, 2016). $\mathrm{Bu}$ araştırmada popüler kültür ürünü olan tarihi dizileri izleyen Sosyal Bilgiler öğretmenleri seçildiği için ölçüt örnekleme kullanılmıştır. Yani araştırmaya katılan öğretmenler en az bir tane tarihi dizi izlemişlerdir. Araştırmaya katılan öğretmenlerin cinsiyet, yaş ve mesleki deneyimlerine ilişkin betimsel veriler Tablo 1'de gösterilmiştir.

Tablo 1.

Sosyal Bilgiler öğretmenlerinin yaşlarına ve mesleki deneyimlerine ait betimsel veriler

\begin{tabular}{|c|c|c|c|c|c|c|c|}
\hline & Yaş & $23-28$ & $29-34$ & $35-40$ & 41-47 & 48 ve üstü & Toplam \\
\hline \multirow[t]{4}{*}{ Cinsiyet } & Kadın & 9 & 10 & 11 & 4 & 2 & 36 \\
\hline & Erkek & 6 & 8 & 9 & 6 & - & 29 \\
\hline & Toplam & 15 & 18 & 20 & 10 & 2 & 65 \\
\hline & $\begin{array}{r}\text { Mesleki } \\
\text { kıdem }\end{array}$ & $0-5$ & 6-10 & $11-15$ & $16-20$ & 21 ve üstü & Toplam \\
\hline \multirow[t]{3}{*}{ Cinsiyet } & Kadın & 11 & 10 & 6 & 6 & 3 & 36 \\
\hline & Erkek & 9 & 6 & 7 & 7 & - & 29 \\
\hline & Toplam & 20 & 16 & 13 & 13 & 3 & 65 \\
\hline
\end{tabular}


Tablo 1'e göre araştırmaya katılan Sosyal Bilgiler öğretmenlerinin 36's1 kadın, 29'u ise erkektir. Araştırmaya toplam 65 sosyal bilgiler öğretmeni katılmıştır. Buna göre araştırmaya katılan öğretmenlerin çoğunluğunu kadın öğretmenler oluşturmaktadır. Kadın ve erkek öğretmenlerden çoğunluğunu 35-40 yaş aralığındaki öğretmenler oluşturmaktadır. Sosyal Bilgiler öğretmenlerinin mesleki deneyimleri incelendiğinde öğretmenlerin büyük bir bölümünün $(\mathrm{f}=20, \operatorname{Kadın}=11$, Erkek=9) 0 5 yıllık bir mesleki deneyime sahip oldukları görülmektedir. 6-10 yıllık mesleki deneyime sahip öğretmenler ( $\mathrm{f}=16, \mathrm{Kadın}=6$, Erkek=7) ise 0-5 yıllık deneyime sahip öğretmenleri izlemektedir.

\section{Veri Toplama Aracı}

$\mathrm{Bu}$ araştırmada veriler yarı yapılandırılmış görüşme formu yoluyla elde edilmiştir. Yarı yapılandırılmış görüşme, araştırmacının görüşme sorularını önceden hazırladığı ancak katılımcıların oluşturulan soruların yeniden düzenlenmesine ve tartışılmasına izin verdiği tekniktir (Ekiz, 2013). Bu tür görüşmelerde sorular hem sabit sorular hem de ilgili alanda derinlemesine bilgi elde edilebilecek sorulardır (Büyüköztürk, Kılıç Çakmak, Akgün, Karadeniz ve Demirel, 2012). Bu çalışmada görüşme formundaki sorular 1 Türkçe, 1 Ölçme Değerlendirme ve 2 adet de alan uzmanının görüşü alınarak oluşturulmuştur. Hazırlanan görüşme soruları ilk olarak 3 Sosyal Bilgiler öğretmeni ile görüşme yapılarak amaca uygun olup olmadığı anlaşılmaya çalışılmıştır. Bu doğrultuda bazı sorular değiştirilmiş, bazı sorulara ise eklemeler yapılarak yeniden düzenlenmiştir. Düzenlenen sorular alan uzmanlarına inceletilerek araştırmaya hazır hale getirilmiştir. Elektronik posta yoluyla görüşme formu Sosyal Bilgiler öğretmenlerine gönderilmiştir. Elektronik postaya 65 Sosyal Bilgiler öğretmeni geri dönüt sağlamıştır.

\section{Verilerin Toplanması ve Analizi}

$\mathrm{Bu}$ araştırmada, elde edilen veriler içerik analizi yolu ile çözümlenmiştir. İçerik analizi; metinlerin düzenlenmesi, sınıflandırılması, karşılaştırılması ve metinlerden teorik sonuçlar çıkarılmasına ve bu sonuçların yorumlanmasına dayanan analiz tekniğidir (Cohen, Manion ve Morrison, 2007). Bu araştırmada analize geçilmeden önce araştırmaya katılan 65 Sosyal Bilgiler öğretmeninin her biri ÖK1, ÖE2, ÖE3...ÖK65 (ÖK-1, Öğretmen kadın-1; ÖE2, Öğretmen erkek-2) şeklinde kodlanmıştır. Daha sonra her bir öğretmenin araştırma sorularına verdikleri cevaplar her soru bazında teker teker analiz edilerek kodlanmıştır. Yapılan bu kodlamalar tekrar gözden geçirilerek benzerlik ve farklılıklarına göre sınıflandırılmıştır. Analiz sırasında iki Sosyal Bilgiler öğretmeninden elde edilen veriler öğretmenlerin sorulara geçerli cevap vermedikleri gerekçesi ile çıkarılmıştır. 63 Sosyal Bilgiler öğretmeninin görüşleri ise geçerli kabul edilmiştir. Yapılan analizler sonucunda elde edilen veriler tablolara aktarılarak yorumlanmıştır.

\section{Geçerlik ve Güvenirlik}

Geçerlik, araştırmada elde edilen verilerin analiz sürecinin ayrıntılı bir şekilde açıklanması ve bulguların tanımlanması olarak açıklanabilir (Yıldırım ve Şimşek, 2016). Bu araştırmada geçerlik, Sosyal Bilgiler öğretmenlerinin görüşlerine ait veriler tablolar halinde sunularak ve doğrudan alıntılara yer verilerek sağlanmaya çalışılmıştır. Ayrıca analiz sürecinde yapılan işlemlerde açıkça belirtilmiştir. Araştırmada güvenirlik, analizci üçgenlemesi yolu ile sağlanmaya çalışılmıştır. Patton (2014) analizci üçgenlemeyi, iki veya daha fazla kişinin verileri bağımsızca analiz etmesi ve elde edilen bulguların karşılaştırılması durumu olarak açıklamaktadır. Bu araştırmada araştırmacılar birbirlerinden bağımsız bir şekilde verileri analiz ederek kodlamışlardır. Veriler tabloya aktarılmadan evvel bir araya gelerek yapılan kodlamalar karşılaştııılmıştır. Farklı düşünülen noktalar tartışılarak bir karara bağlanmıştır. Miles ve Huberman (1994) tarafından formüle edilen uzlaşma yüzdesi (Uzlaşma yüzdesi=Görüş Birliği/(Görüş Birliği+Görüş Ayrılığı)x100 oranının \%80'e yakın olması tavsiye edilmektedir. Bu araştırmada araştırmacılar tarafından yapılan kategoriler karşılaştırılmış ve aynı kategoriler, görüş birliği olarak, farklı kategoriler ise görüş ayrılığı olarak belirlenmiş ve her soru için ayrı ayrı güvenirlik hesaplaması yapılmıştır. Buna göre; Uzlaşma yüzdesi= 159/159+10x100=94 olarak hesaplanmıştır.

\section{BULGULAR}


Araştırmanın bu bölümünde Sosyal Bilgiler öğretmenlerin tarihi dizilere ilişkin görüşlerine yer verilmektedir. Bu doğrultuda Sosyal Bilgiler öğretmenlerinin araştırma sorularına verdikleri cevaplar incelenerek tablolara aktarılmıştır.

\subsection{Birinci Alt Probleme İlişkin Bulgular}

Araştırmanın birinci alt problemi “Öğretmenlerin izledikleri güncel tarihi diziler nelerdir?” şeklindedir. Tablo 2'de Sosyal Bilgiler öğretmenlerinin araştırmanın bu sorusuna verdikleri cevaplara ilişkin bulgulara yer verilmektedir

Tablo, şekil vb. kullanılması durumunda verilen örneğe uygun bir şekilde düzenlenmelidir. Tablo ve şekiller 1'den başlayarak numaralandırılmalı ve adlandırılmalıdır. Varsa kaynak altta belirtilmelidir.

Tablo 2.

Öğretmenlerin izledikleri güncel tarihi dizilere ilişkin betimsel veriler

\begin{tabular}{cccc}
\hline Tarihi diziler & Kadın & Erkek & Toplam \\
\hline Diriliş Ertuğrul & 12 & 19 & 31 \\
Vatanım Sensin & 15 & 5 & 20 \\
Payitaht Abdülhamit & 5 & 7 & 12 \\
Mehmetçik Kut’ül Amare & 1 & 4 & 5 \\
Vikingler & 1 & 2 & 3 \\
Aliya & 1 & - & 1 \\
Toplam & 35 & 37 & 72 \\
\hline
\end{tabular}

Araştırmanın bu problemini öğretmenler 6 farklı şekilde cevaplamışlardır. Buna göre öğretmenler güncel tarihi dizilerden Diriliş Ertuğrul $(\mathrm{f}=31)$, Vatanım Sensin $(\mathrm{f}=20)$, Payitaht Abdülhamit ( $\mathrm{f}=12)$, Mehmetçik Kut'ül Amare $(\mathrm{f}=5)$, Vikingler $(\mathrm{f}=3)$ ve Aliya $(\mathrm{f}=1)$ dizilerini izlediklerini belirtmişlerdir. Bu diziler içinde ise en fazla izlenen dizinin Diriliş Ertuğrul $(\mathrm{f}=31$, Kadın=12, Erkek=19) dizisi olduğu görülmektedir. Bu tarihi diziyi Vatanım Sensin ( $\mathrm{f}=20$, Kadın=15, Erkek=5) dizisi takip etmektedir. $\mathrm{Bu}$ tarihi dizilerin izlenme durumları cinsiyet bakımından incelendiğinde ise kadın öğretmenlerin daha çok Vatanım Sensin dizisini, erkek öğretmenlerin ise Diriliş Ertuğrul dizisini izledikleri söylenebilir. Ayrıca öğretmenlerden bazılarının yabancı yapım filmleri de izledikleri görülmektedir. Araştırmaya katılan öğretmenlerden bazıları araştırmanın bu sorusunu şu şekilde cevaplamışlardır:

ÖE-3: "Takip edebildiğim kadarıyla Payitaht,Vatanım Sensin ve Diriliş Ertuğrul."

ÖE-23: "Güncel tarihi dizilerden Diriliş Ertuğrul ve Payitaht Abdülhamit dizilerini izliyorum."

ÖE-35: "Vatanım Sensin ve Diriliş Ertuğrul dizilerini izliyorum."

ÖE-37: "Kut'ül Amare Mehmetçik dizisi."

ÖK-38: "Aliya dizisini takip ediyorum."

ÖK-62: "Vikingleri izlemeye çalışıorum."

ÖK-63: "Diriliş Ertuğrul ve Payitaht Abdülhamid'i izliyorum."

Bazı öğretmenlerin sadece bir tarihi diziyi takip ettikleri, bazı öğretmenlerin ise birden fazla tarihi diziyi takip ettikleri görülmektedir. Ayrıca öğretmenlerin hangi tarihi diziyi izledikleri cinsiyetlerine göre de değişmektedir.

\section{2. İkinci Alt Probleme İlişkin Bulgular}

Araştırmanın ikinci alt problemi "Öğretmenlerin geçmişte izledikleri tarihi diziler nelerdir?" şeklindedir. Araştırmanın bu sorusuna ilişkin bulgulara Tablo 3'te yer verilmektedir. 
Tablo 3.

Öğretmenlerin geçmişte izledikleri tarihi dizilere ilişskin betimsel veriler

\begin{tabular}{cccc}
\hline Tarihi diziler & Kadın & Erkek & Toplam \\
\hline Muhteşem Yüzyıl & 17 & 15 & 32 \\
Filinta & 1 & 7 & 8 \\
Kuruluş "Osmancık" & 3 & 3 & 6 \\
Spartacus & 1 & 1 & 2 \\
Hatırla Sevgili & - & 2 & 2 \\
Sevda Kuşun Kanadında & - & 2 & 2 \\
Kurt Kanunu & - & 1 & 1 \\
IV.Murat & - & 1 & 1 \\
Muhteșem Yüzyıl Kösem Sultan & 1 & - & 1 \\
Yedi Güzel Adam & - & 1 & 1 \\
Bu Kalp Seni Unutur mu? & - & 1 & 1 \\
Kurşun Yarası & - & 1 & 1 \\
Yunus Emre Aşkın Yolculuğu & - & 1 & 1 \\
Çemberimde Gül Oya & - & 1 & 1 \\
Marco Polo & - & 1 & 1 \\
Da Vinci's Demas & - & 1 & 1 \\
Black Sails & - & 1 & 1 \\
Seksenler & - & 1 & 1 \\
Elveda Rumeli & 1 & - & 1 \\
Toplam & 24 & 33 & 65 \\
\hline
\end{tabular}

Tablo 3'te Sosyal Bilgiler öğretmenlerinin geçmişte izledikleri tarihi diziler incelenmiştir. Sosyal Bilgiler öğretmenleri araştırmanın bu sorusunu 19 farklı şekilde cevaplamışlardır. Öğretmenlerin geçmişte daha çok Muhteşem Yüzyıl ( $\mathrm{f}=26, \mathrm{Kad} ı$ =17, Erkek=9), Filinta ( $\mathrm{f}=1, \mathrm{Kad} ı$ n=6, Erkek=7) ve Kuruluş "Osmancık" ( $\mathrm{f}=5$, Kadın=3, Erkek=2) dizilerini izledikleri görülmektedir. Muhteşem Yüzyıl (Kadın=17, Erkek=9) ve Kuruluş "Osmancık" (Kadın=3, Erkek=2) dizisini daha çok kadın öğretmenlerin izlediği söylenebilir. Ayrıca öğretmenlerin sadece geçmiş yerli tarihi dizileri değil aynı zamanda geçmiş yabancı tarihi dizileri de takip ettikleri görülmektedir. Araştırmaya katılan ögretmenlerden bazıları araştırmanın bu sorusunu şöyle cevaplamışlardır:

ÖE-9: "Muhteşem Yüzyıl, Muhteşem Yüzyıl Kösem Sultan, Hatırla Sevgili, Kurt Kanunu, IV Murad ve Kuruluş Osmancık'ı izlemiştim."

ÖE-17: "Seksenler dizisini izliyordum."

ÖK-25: "Osmancık ve Muhteşem Yüzy1l dizilerini izledim."

ÖE-30: "Yedi Güzel Adam, Filinta ve Muhteşem yüzyıl dizileri."

ÖK-42: "Elveda Rumeli dizisini izlemiştim."

ÖE-43: "Filinta ve Yunus Emre Aşkın Yolunda."

ÖE-53: "Muhteşem Yüzyıl'ı izledim."

Öğretmenler geçmişte en fazla Muhteşem Yüzyıl tarihi dizisini izlediklerini belirtmişlerdir. Bu dizi dışında Yedi Güzel Adam, Filinta, Elveda Rumeli, Yunus Emre Aşkın Yolunda, Seksenler gibi tarihi dizileri de bazı öğretmenlerin izledikleri görülmektedir. Bazı öğretmenler sadece bir tarihi dizi izlerken bazı öğretmenler ise birden fazla tarihi diziyi izlemişlerdir.

\section{3. Üçüncü Alt Probleme İlişkin Bulgular}

Araştırmanın üçüncü alt problemi "Öğretmenlerin izledikleri güncel tarihi dizilerin konuları nelerdir?" ş̧eklindedir. Sosyal Bilgiler öğretmenlerinin araştırmanın bu sorusuna ilişkin verdikleri cevaplara ilişkin bulgular Tablo 4'te yer almaktadır. 
Tablo 4.

Öğretmenlerin izledikleri güncel tarihi dizileri dizilerin konularına ilişkin betimsel veriler

\begin{tabular}{|c|c|c|c|c|}
\hline Tarihi diziler & & Kadın & Erkek & Toplam \\
\hline \multirow{8}{*}{ Diriliş Ertuğrul } & Osmanlı'nın kuruluşu & 8 & 7 & 15 \\
\hline & Kayı boyunun Anadolu'daki serüveni & 1 & 2 & 3 \\
\hline & Osmanlı tarihi & - & 3 & 3 \\
\hline & Ertuğrul Gazi dönemi & 1 & 2 & 3 \\
\hline & Anadolu'da Türk tarihi & - & 2 & 2 \\
\hline & Anadolu Selçuklu tarihi & - & 2 & 2 \\
\hline & Devlet yönetimi & 1 & - & 1 \\
\hline & Bizans oyunları & 1 & - & 1 \\
\hline \multirow{7}{*}{ Vatanım Sensin } & Türk-İslam kültürü & - & 1 & 1 \\
\hline & Kurtuluş Savaşı & 11 & 1 & 12 \\
\hline & Milli mücadele & 2 & 1 & 3 \\
\hline & Vatanseverlik & 2 & - & 2 \\
\hline & Osmanlı tarihi & 1 & - & 1 \\
\hline & Devlet yönetimi & 1 & - & 1 \\
\hline & Mustafa Kemal Atatürk & 1 & - & 1 \\
\hline \multirow{5}{*}{ Payitaht Abdülhamit } & Osmanlı tarihi & 2 & 3 & 5 \\
\hline & Osmanlı Devleti'nin dağılma dönemi & 1 & 1 & 2 \\
\hline & II.Abdülhamit dönemi & 1 & 1 & 2 \\
\hline & Siyasi olaylar & 1 & - & 1 \\
\hline & Aşk & 1 & - & 1 \\
\hline \multirow[t]{2}{*}{ Mehmetçik Kut'ül Amare } & I.Dünya Savaşı & - & 3 & 3 \\
\hline & Osmanlı Devleti & - & 1 & 1 \\
\hline \multirow[t]{2}{*}{ Vikingler } & Vikinglerin tarihi & 1 & - & 1 \\
\hline & Vikinglerin sosyal yaşantıları & - & 1 & 1 \\
\hline Aliya & Bosna bağımsızlık mücadelesi & 1 & - & 1 \\
\hline Toplam & & 37 & 31 & 68 \\
\hline
\end{tabular}

Öğretmenler araştırmanın bu sorusuna izlemekte olduğu tarihi diziye göre farklı şekillerde cevaplamışlardır. Buna göre Sosyal Bilgiler öğretmenleri Diriliş Ertuğrul dizisinin konusunu "Osmanlı'nın kuruluşu" ( $\mathrm{f}=15)$; Vatanım Sensin dizisinin konusunu "Kurtuluş Savaşı" ( $\mathrm{f}=12$ ); Payitaht Abdülhamit dizisinin konusunu "Osmanlı tarihi” (f=5) ve Mehmetçik Kut'ül Amare dizisinin konusu "I.Dünya Savaşı" ( $\mathrm{f}=3$ ) olarak belirtmektedirler. Öğretmenlerin Diriliş Ertuğrul ve Vatanım Sensin dizilerinin konularını daha çok sayıda ve farklı şekillerde ifade ettikleri görülmektedir. Bu durum bu iki tarihi diziyi izleyenlerin daha fazla olması ile açıklanabilir. Araştırmaya katılan öğretmenlerden bazıları araştırmanın bu sorusunu şöyle cevaplamışlardır:

ÖK-13: "Vatanım Sensin dizisini izliyorum. Bu dizinin konusu Kurtuluş Savaşı'dır."

ÖE-15: "Diriliş Ertuğrul dizisi. Bu dizinin konusu Osmanlı'nın kuruluşudur."

ÖK-24: "Diriliş Ertuğrul dizisini izliyorum. Bizans oyunları ve devlet yönetimi dizinin konularıdır."

ÖK-34: "Payitaht Abdülhamit dizisini takip ediyorum. Konusu Osmanlı'nın siyasi olaylarıdır."

ÖE-31: "Kut'ül Amare'yi izliyorum. I.Dünya Savaşı'nı anlatıyor."

ÖE-35: "Diriliş Ertuğrul dizisini izliyorum. Konusu Kayı boyunun Anadolu'daki serüveni."

ÖK-60: "Vatanım Sensin dizisini takip ediyorum. Konusu bağımsızlık, mücadele ve vatanseverlik."

ÖE-61: "Diriliş dizisi Osmanlı'nın kuruluş, Payitaht Abdülhamit de dăğlma dönemini anlatiyor."

Öğretmenlerin doğrudan görüşleri incelendiğinde bazı öğretmenler izledikleri tarihi dizilerin konularını daha genel çerçevede ifade etmişleridir. Örneğin; bağımsızlık, mücadele, vatanseverlik gibi. Bazı öğretmenler ise daha özel bakış açısıyla görüşlerini belirtmişlerdir. Örneğin; Kayı boyunun Anadolu'daki serüveni. 


\subsection{Dördüncü Alt Probleme İlişkin Bulgular}

Araştırmanın dördüncü alt problemi "Öğretmenler tarihi dizilerdeki hangi karakterlerden etkilenmişlerdir? Neden?" şeklindedir. Sosyal Bilgiler öğretmenlerinin araştırmanın bu sorusuna ilişkin verdikleri cevaplara ilişkin bulgular Tablo 5 ve Tablo 6'da yer almaktadır:

Tablo 5 .

Öğretmenlerin izlemekte oldukları tarihi dizilerdeki etkilendikleri karakterlere iliş̧kin betimsel veriler

\begin{tabular}{lcccc}
\hline Tarihi diziler & Karakter & Kadın & Erkek & Toplam \\
\hline \multirow{4}{*}{ Diriliş Ertuğrul } & Ertuğrul & 4 & 11 & 15 \\
& Artuk Bey & 2 & 2 & 4 \\
& Bamsi Beyrek & 1 & 3 & 4 \\
& Halime Hatun & 2 & 1 & 3 \\
& Hayme Ana & 3 & - & 3 \\
& Turgut Alp & 2 & 1 & 3 \\
& İbn'ül Arabi & 1 & - & 1 \\
Vatanım Sensin & Albay Cevdet & 4 & 2 & 6 \\
& Hilal & 5 & - & 5 \\
& Azize Hemşire & 3 & - & 3 \\
\multirow{3}{*}{ Payitaht Abdülhamit } & Hasibe Ana & 2 & - & 2 \\
\multirow{3}{*}{ Mehmetçik Kut' ül Amare } & Leon & 2 & - & 2 \\
\multirow{3}{*}{ Aliya } & Sütçü Ramiz & 1 & - & 1 \\
Vikingler & II. Abdülhamit & 3 & 3 & 6 \\
Toplam & Tahsin Paşa & - & 1 & 1 \\
& Süleyman Asker & - & 1 & 1 \\
& Hüsrevoğlu Mehmet & - & 1 & 1 \\
& Aliya İzzet Begoviç & 1 & - & 1 \\
& Ragnar & 1 & - & 1 \\
& & 37 & 25 & 62 \\
\hline
\end{tabular}

Tablo 5 incelendiğinde öğretmenlerin izlemekte oldukları dizilerden daha çok Diriliş Ertuğrul (Ertuğrul, Artuk Bey, Bamsı Beyrek, Halime Hatun, Hayme Ana, Turgut Alp ve İbn'ül Arabi) ve Vatanım Sensin (Albay Cevdet, Hilal, Azize Hemşire, Hasibe Ana, Leon ve Sütçü Ramiz) tarihi dizi karakterlerinden etkilendikleri görülmektedir. Buna göre öğretmenlerin en fazla etkilendikleri karakterin Diriliş Ertuğrul dizisi karakteri Ertuğrul $(\mathrm{f}=15, \mathrm{Kad} ı n=4$, Erkek=11) olduğu görülmektedir. Bu karakteri Vatanım Sensin dizisi karakteri Albay Cevdet $(\mathrm{f}=4, \mathrm{Kad} ı n=2$, Erkek=6) ve Payitaht Abdülhamit dizisi karakteri II. Abdülhamit ( $\mathrm{f}=4, \mathrm{Kadın}=2$, Erkek=6) karakterleri izlemektedir. Kadın öğretmenlerin en fazla etkilendiği dizi karakterlerinin sırasıyla Hilal ( $\mathrm{f}=5)$, Ertuğrul ( $\mathrm{f}=4)$ ve Albay Cevdet $(\mathrm{f}=4)$ karakterleri; erkek öğretmenlerin ise sirasıyla Ertuğrul $(\mathrm{f}=11)$, Bamsı Beyrek $(\mathrm{f}=3)$ ve II. Abdülhamit $(\mathrm{f}=3)$ karakterlerinden etkilenmişlerdir.

Tablo 6.

Öğretmenlerin izlemekte oldukları dizilerdeki karakterlerden etkilenme nedenlerine ilişsin betimsel veriler

\begin{tabular}{lccc}
\hline Görüşler & Kadın & Erkek & Toplam \\
\hline Vatan-millet sevgisini ön planda tutmaları & 8 & 13 & 21 \\
Türk kadınına örnek olmaları & 15 & - & 15 \\
Cesur, akıllı, dürüst ve adil olmaları & 6 & 5 & 11 \\
Zalimlerle mücadele etmeleri & 2 & 5 & 7 \\
Entrikalara karşı akıllıca siyaset izlemeleri & 3 & 4 & 7 \\
İyi bir savaşçı ve sadık bir asker olmaları & 1 & 4 & 5 \\
Araştıran ve sorgulayan Türk kadını olmaları & 5 & - & 5 \\
Bilge olmaları & 2 & 2 & 4 \\
Toplumun içinden bir karakteri yansıtmaları & 3 & - & 3 \\
Milli şuuru/bilinci iyi işlemeleri & - & 1 & 1
\end{tabular}


Öğretmenler izlemekte oldukları dizilerdeki karakterlerden etkilenme nedenlerini farklı bakıș açıları ile açıklamışlardır. Buna göre öğretmenler karakterlerden etkilenme nedenlerini en fazla sırasıyla "Vatan-millet sevgisini ön planda tutmaları" ( $\mathrm{f}=21, \mathrm{Kad} ı n=8$, Erkek=13); "Türk kadınına örnek olmaları" ( $\mathrm{f}=15$, Kadın=15) ve "Cesur, akıllı, dürüst ve adil olmaları" ( $\mathrm{f}=11$, Kadın=5, Erkek=5) şeklinde belirtirler. Kadın öğretmenler karakterlerden etkilenme nedenlerini en fazla "Türk kadınına örnek olmaları" (Kadın=15) ve "Vatan-millet sevgisini ön planda tutmaları" $(\mathrm{K}=8)$; erkek öğretmenler ise "Vatan-millet sevgisini ön planda tutmaları" (Erkek=13), "Cesur, akı1ll, dürüst ve adil olmaları" $($ Erkek $=5)$ ve "Zalimlerle mücadele etmeleri" $(\mathrm{f}=5)$ durumlarına dayandırmaktadırlar. Araştırmaya katılan öğretmenlerden bazıları etkilendikleri dizi karakterini ve nedenini şöyle açıklamışlardır:

ÖE-3: "Ertuğrul karakterini beğeniyorum. Kahramanlığı beni etkiliyor."

ÖE-7: "Bamsı Beyrek hoşuma gidiyor. İyi bir savaşçı."

ÖK-11: "Hilal karakteri çünkü araştıran sorgulayan bir Türk kızını canlandırıyor."

ÖK-13: "Abdülhamit. Çünkü başında onca entrika olmasına rağmen üstesinden geliyor."

ÖK-28: "Vatanım Sensin dizisindeki Cevdet Albay. Ülkesi için fedakârlıklar yapması."

ÖK-37: "Abdülhamid Han, güçlü bir karakter olması."

ÖK-46: "Artuk Bey. Sakin ve bilge oluşu."

ÖK-51: "Hayme Ana, Türk kadınının kudretini ortaya koyuyor."

ÖK-54: "Mustafa Kemal Atatürk, İsmet İnönü, Kazım Karabekir, Kara Fatma, Cevdet, Azize, Hilal ve arkadaşları, Hasan Tahsin, Mehmet Akif Ersoy, Ertuğrul Gazi, Bamsı, Turgut, Halime Sultan, Hayme Ana, Artuk Bey, İbn'ül Arabi ...kısaca doğruluk, iyilik, hak, hukuk için, adalet için mücadele eden, vatanı için gözünü kırpmadan can vermeye hazır olan, vatan için, insanlık için, çocuklar için çabalayan herkesten etkilenmemek mümkün değil. Hepsi çok değerli bence.”

Öğretmenlerin etkilendikleri tarihi dizi karakterlerinin vatan ve millet sevgisi ile ön plana çıktığı görülmektedir. Ayrıca bazı öğretmenlerde dizi karakterlerinin ise baskın karakter özelliklerinden etkilendiği de söylenebilir.

\subsection{Beșinci Alt Probleme İlişkin Bulgular}

Araştırmanın beşinci alt problemi "Öğretmenlere göre tarihi dizilerle gerçek tarih arasında fark var mıdır?" şeklindedir. Sosyal Bilgiler öğretmenlerinin araştırmanın bu sorusuna iki farklı şekilde cevaplamışlardır. Öğretmenlerin araştırmanın bu sorusuna ilişkin verdikleri cevaplara ilişkin bulgular Tablo 7 ve Tablo 8'de yer almaktadır:

Tablo 7.

Güncel tarihi diziler ile tarihi gerçekler arasındaki fark olduğunu düşünen ögrretmenlerin görüşlerine ilişkin betimsel veriler

\begin{tabular}{|c|c|c|c|c|}
\hline Tarihi diziler & Görüşler & Kadın & Erkek & Toplam \\
\hline \multirow{12}{*}{ Diriliş Ertuğrul } & Gerçek olayların üzerine kurgulanmaması & 4 & 3 & 7 \\
\hline & Reyting kaygısı ile gerçeğin magazinsel sunulması & 1 & 4 & 5 \\
\hline & Kronolojik olarak siralama hataları mevcut & 3 & 1 & 4 \\
\hline & Döneme ait kaynakların az olması & - & 3 & 3 \\
\hline & Kişilerin değiştirilmesi, hayali kahramanların yaratılması & 2 & - & 2 \\
\hline & Özüne sadık kalınarak eklemeler yapılması & 2 & - & 2 \\
\hline & Hükümetin siyasal ideolojisine göre şekillendirilmesi & - & 1 & 1 \\
\hline & Popüler kültüre hizmet etmesi & 1 & - & 1 \\
\hline & Dizilerin sıkıcı olmaktan çıkarılması & - & 1 & 1 \\
\hline & Olayların fazla romantizm ve lirizm içermesi & 1 & - & 1 \\
\hline & Gerçek olayların üzerine kurgulanmaması & 6 & 2 & 8 \\
\hline & Reyting kaygısı ile gerçeğin magazinsel sunulması & 3 & - & 3 \\
\hline \multirow{3}{*}{ Vatanım Sensin } & Olayların fazla romantizm ve lirizm içermesi & 1 & - & 1 \\
\hline & Kronolojik olarak siralama hataları mevcut & 1 & - & 1 \\
\hline & Popüler kültüre hizmet etmesi & 1 & - & 1 \\
\hline
\end{tabular}




\begin{tabular}{|c|c|c|c|c|}
\hline & Kişilerin değiştirilmesi, hayali kahramanların yaratılması & 1 & - & 1 \\
\hline & Gerçek olayların üzerine kurgulanmaması & - & 4 & 4 \\
\hline Payitaht & Tarihi olayların değiştirilmesi & 1 & 1 & 2 \\
\hline \multirow[t]{3}{*}{ Abdülhamit } & Popüler kültüre hizmet etmesi & 1 & - & 1 \\
\hline & Dizilerin sıkıcı olmaktan çıkarılması & - & 1 & 1 \\
\hline & Reyting kaygısı ile gerçeğin magazinsel sunulması & - & 1 & 1 \\
\hline \multirow{3}{*}{$\begin{array}{l}\text { Mehmetçik Kut'ül } \\
\text { Amare }\end{array}$} & Gerçek olayların üzerine kurgulanmaması & - & 2 & 2 \\
\hline & Reyting kaygısı ile gerçeğin magazinsel sunulması & - & 2 & 2 \\
\hline & Dizilerin sıkıcı olmaktan çıkarılması & - & 1 & 1 \\
\hline \multirow[t]{2}{*}{ Vikingler } & Dizilerin sıkıcı olmaktan çıkarılması & - & 2 & 2 \\
\hline & Gerçek olayların üzerine kurgulanmaması & - & 1 & 1 \\
\hline Aliya & Bosnalılara yapılan zulümlerin yeterince gösterilmemesi & 1 & - & 1 \\
\hline Toplam & & 30 & 30 & 60 \\
\hline
\end{tabular}

Öğretmenler araştırmanın bu sorusunu izlemekte oldukları her bir dizi için farklı şekillerde cevaplamışlardır. Öğretmenler Diriliş Ertuğrul tarihi dizisinin "Gerçek olayların üzerine kurgulanmaması" ( $\mathrm{f}=7, \mathrm{Kad} ı n=4$, Erkek=3) ve "Reyting kaygısı ile gerçeğin magazinsel sunulması" $(\mathrm{f}=5, \mathrm{Kad} ı n=1$, Erkek=4); Vatanım Sensin dizisinin "Gerçek olayların üzerine kurgulanması" ( $\mathrm{f}=8$, Kadın=6, Erkek=2) ve "Reyting kaygısı ile gerçeğin magazinsel sunulması" ( $f=3$, Kadın=3) ve Payitaht Abdülhamit dizisinin "Gerçek olayların üzerine kurgulanması" ( $\mathrm{f}=4$, Erkek=4) ve "Tarihi olayların değiştirilmesi” ( $\mathrm{f}=2, \quad \mathrm{Kad} ı n=1, \quad$ Erkek=1) gibi nedenlerle gerçekle arasında fark olduğunu düşünmektedirler. Araştırmaya katılan öğretmenlerden bazıları araştırmanın bu sorusunu şu şekilde cevaplamışlardır:

ÖE-3: "Dizilerde olayı sanatsallaştırmak adına fazla romantizm yapıyorlar. İzleyicinin duygularına hitap etmek için fazla lirizm içeriyor."

ÖE-18: "Kurmacalar var ancak gerçek olaylar üzerine tasarlanmış."

ÖK-20: "Var tabiki. Sonuçta diziler birer kurgu. Varolan gerçekler üzerinden bir hikaye yaz1lyyor."

ÖE-24: "Dizilerde olayı sanatsallaştırmak adına değişiklikler yapıldığını düşünüyorum."

ÖE-25: "Elbette var. Dizi başlarken daha fazla gerçeğe bağlı kalınıyordu. Zamanla reyting uğruna değişikliğe gidilmiştir."

ÖK-30: "Evet dizilerde kronolojik olarak sıkıntılar olduğunu fark ediyorum."

ÖE-38: "Elbette bir takım eklemeler ve çıkarmalar yapılıyor."

ÖK-44: "Kişiler değiştiriliyor. Diziye hayali kahramanlar ekleniyor."

ÖK-55: "Konu itibariyle ana hatlar aynı ama tabi ki dizi olduğu için bazı farklılıklar olabiliyor senaryo zenginleştirilsin vs diye. Kısaca elde olan bilgiler ışığında, bağlantı kurabilecek boşluklar hayal güçlerine göre dolduruluyor."

ÖK-58: "Gerçek Bosna tarihine göre Müslümanlara yapılan haksızlıklar, zulümler yeterince gösterilmedi."

Öğretmenler izledikleri tarihi dizilerin gerçek olaylar üzerine kurgulandığını ve reyting elde etmek için gerçeklere sadık kalınmadığını düşünmektedirler.

Tablo 8 .

Tarihi diziler ile tarihi gerçekler arasındaki fark olmadığını düşünen öğretmenlerin görüşlerine iliş̧kin betimsel veriler

\begin{tabular}{llccc}
\hline Tarihi diziler & Görüşler & Kadın & Erkek & Toplam \\
\hline Diriliş Ertuğrul & Tarihi olayları doğrudan aktarması & - & 2 & 2 \\
Vatanım Sensin & Tarihi gerçekliğe uygun aktarılması & - & 1 & 1 \\
Payitaht Abdülhamit & Belgelere ulaşılabildiği için doğru aktarılması & - & 1 & 1 \\
& Tarihi kişi ve mekânlara bağlı kalınması & - & 1 & 1 \\
Mehmetçik Kut'ül Amare & Gerçeğe uygun tasarlanması & - & 1 & 1 \\
Toplam & & - & 6 & 6 \\
\hline
\end{tabular}


Öğretmenlerden bazıları tarihi diziler ile gerçekler arasında fark olmadığını belirtmişlerdir. Öğretmenler Diriliș Ertuğrul dizisinde "Tarihi olayları doğrudan aktarması" ( $\mathrm{f}=2$, Erkek=2); Vatanım Sensin dizisinde "Tarihi gerçekliğe uygun aktarılması" ( $\mathrm{f}=1$, Erkek=1); Payitaht Abdülhamit dizisinde "Belgelere ulaşılabildiği için doğru aktarılması" (f=1, Erkek=1) ve "Tarihi kişi ve mekânlara bağlı kalınması" (f=1, Erkek=1); Mehmetçik Kut'ül Amare dizisinde ise "Gerçeğe uygun tasarlanması" ( $\mathrm{f}=1$, Erkek=1) şeklinde görüşlerini belirtmişlerdir. Araştırmaya katılan öğretmenlerden bazıları araştırmanın bu sorusunu şu şekilde cevaplamışlardır:

ÖE-16: "Diriliş Ertuğrul dizisinde illaki vardır. Çünkü döneme ait belgeler oldukça kısıtlıdır ki bu durum yapım ekibi tarafından açıklanmıştı zaten. Ana işleyişi bozmadan ve birçok gerçek karakterle yoluna devam etmektedir. Payitaht dizisinin geçtiği dönem oldukça bilindik olduğundan genelde tarihe uyumlu olduğu söylenebilir."

ÖE-35: "İzlediğim dizilerde şu an için değişiklik olduğunu düşünmüyorum."

ÖE-33: "Tarihi gerçekliğe genelde uygun gidiyor."

ÖK-35: "Çok farklılık yok. Yaşanmışlık ile bire bir aynı olmayabilir. Ancak değiştirirlerse izlemezler diye düşünüyorum."

ÖE-41: "Bence fark yok. Zaman, mekân ve kişiler aynı."

Öğretmenlerden bazıları izledikleri tarihi dizilerde tarihi gerçeklere uygun gidildiğinden ve bu dizilerde herhangi bir değişikliğe gidilmediğinden bahsetmektedirler. Bu durum bazı öğretmenlerin tarihi dizilerin tarihi gerçeklerle uyumlu olduğu görüşlerini doğrulamaktadır.

\subsection{Altıncı Alt Probleme İlişkin Bulgular}

Araştırmanın altıncı alt problemi "Öğretmenler tarihi dizilerle ilgili derslerinde nasıl örnekler veriyorlar? şeklindedir. Öğretmenlerin araştırmanın bu sorusuna ilişkin verdikleri cevaplara ilişkin bulgular Tablo 9'da yer almaktadır:

Tablo 9.

Öğretmenlerin derslerinde tarihi dizilerle ilgili verdikleri örneklere ilişkin betimsel veriler

\begin{tabular}{|c|c|c|c|c|}
\hline Tarihi diziler & Görüşler & Kadın & Erkek & Toplam \\
\hline \multirow{11}{*}{ Diriliş Ertuğrul } & Yaşam tarzları & 3 & 2 & 5 \\
\hline & Töre ve kurultay & 2 & 3 & 5 \\
\hline & Ekonomik faaliyetler & 2 & - & 2 \\
\hline & Ordu teşkilatı/Askeri yapı & - & 2 & 2 \\
\hline & Osmanlı kuruluş dönemi & 1 & 1 & 2 \\
\hline & Kilık-k1yafet & 1 & 1 & 2 \\
\hline & Tarihi şahsiyetler & - & 1 & 1 \\
\hline & Divan teşkilatı & - & 1 & 1 \\
\hline & Gaza-Cihat anlayışı & 1 & - & 1 \\
\hline & Atın Türkler için önemi & - & 1 & 1 \\
\hline & Türklerin adalet anlayışı & - & 1 & 1 \\
\hline \multirow{7}{*}{ Vatanım Sensin } & Kılık-kıyafet & 2 & - & 2 \\
\hline & Tarihi olaylar & 1 & 1 & 2 \\
\hline & Atın Türkler için önemi & - & 1 & \\
\hline & İzmir'in işgali & 1 & - & 1 \\
\hline & Yaşam tarzları & 1 & - & 1 \\
\hline & Ekonomik faaliyetler & 1 & - & 1 \\
\hline & Amasya Genelgesi'nin okunması & 1 & - & 1 \\
\hline \multirow{9}{*}{ Payitaht İstanbul } & Savaş sahneleri & 1 & - & 1 \\
\hline & Divan teşkilatı & 1 & - & 1 \\
\hline & Cülus töreni & 1 & - & 1 \\
\hline & Devşirme sistemi & 1 & - & 1 \\
\hline & Yaşam tarzları & - & 1 & 1 \\
\hline & Devlet yönetimi & - & 1 & 1 \\
\hline & Ordu teşkilatı/Askeri yapı & - & 1 & 1 \\
\hline & Kil1k-kiyafet & - & 1 & 1 \\
\hline & Türklerin adalet anlayıșı & - & 1 & 1 \\
\hline
\end{tabular}


Öğretmenlerin araştırmanın bu sorusunu izledikleri diziye göre farklı şekillerde cevapladıkları görülmektedir. Buna göre öğretmenler Diriliş Ertuğrul tarihi dizisinde "yaşam tarzları" ( $\mathrm{f}=5$, Kadın=3, Erkek=2) ve "töre ve kurultay" (f=5, Kadın=2, Erkek=3); Vatanım Sensin dizisinde "kılık-kıyafet" $(\mathrm{f}=2, \mathrm{Kad} ı n=2)$ ve "tarihi olaylar" $(\mathrm{f}=2, \mathrm{Kad} ı n=1$, Erkek=1) durumları ile ilgili örnek verdiklerini belirtmişlerdir. Kadın öğretmenler en fazla Diriliş Ertuğrul dizisinden "yaşam tarzları" (Kadın=3); erkek öğretmenler ise Diriliş Ertuğrul dizisi ile ilgili "töre ve kurultay" (Erkek=3) konularını örnek vermektedirler. Araştırmaya katılan öğretmenlerden bazıları araştırmanın bu sorusunu şu şekilde cevaplamışlardır:

ÖE-6: "Evet, 6.sınıflarda Türk kültürüyle ilgili töre-kurultay gibi konularda örnekler veriyorum."

ÖE-8: "Vatanım Sensin dizisinde İzmir'in işgalini örnek vermiştim."

ÖK-12: "Diriliş Ertuğrul dizisinde giyim kuşam ve tarihi olaylarla ilgili örnekler veriyorum."

ÖK-30: "Evet veriyorum. Mesela İpek Yolu'nda Türkler ünitesinde eski Türklerin yaşam biçimi, bozkır yaşam tarzı, çadırlarda yaşamaları, ekonomik faaliyet olarak hayvancılıkla uğraşmaları, halı, kilim dokuması, toy (kurultay) denilen danışma meclisi vb. konuları işlerken Diriliş Ertuğrul dizisini izleyen olup olmadığını soruyorum. İzlemelerini tavsiye ediyorum. Bu konuları daha iyi kavramaları konusunda yardımcı olabileceğini söylüyorum."

ÖE-33: "Veriyorum. Mesela kurultay, otağ, göçebe kültürü, töre kavramlarında iyi örnek teşkil ediyor."

ÖE-38: "Evet, Diriliş Ertuğrul dizisinde Türklerin yaşam tarzıyla ilgili örnek veriyorum."

ÖK-58: "Cülus, divan teşkilatı, töre ve toyu örneklendirmek için bu dizilerden faydalanıyorum."

ÖK-61: "Evet veriyorum. Özellikle Diriliş Ertuğrul dizisinin dizi platformu gerçeğe çok yakın. Türk töresi ve eski Türkçe kelimelerde dikkat çekici olabiliyor. Bu örnekler görselliğe ve bir kurguya dayalı olduğu için kalıcılık sağlanabiliyor."

Öğretmenler tarihi olay ve durumları somutlaştırmak için tarihi dizilerden çeşitli durumları örnek gösterdiklerini belirtmektedirler.

\subsection{Yedinci Alt Probleme İlişskin Bulgular}

Araştırmanın yedinci alt problemi "Öğretmenlere göre tarihi dizilerin toplumsal yaşama etkileri nelerdir?" şeklindedir. Öğretmenlerin araştırmanın bu sorusuna ilişkin verdikleri cevaplara ilişkin bulgular Tablo 10'da yer almaktadır:

Tablo 10.

Öğretmenlere göre tarihi dizilerin toplumsal yaşama etkilerine ilişkin betimsel veriler

\begin{tabular}{lccc}
\hline Görüşler & Kadın & Erkek & Toplam \\
\hline İnsanların tarihe merakını/ilgisini artırması & 9 & 7 & 16 \\
İnsanları kendi tarihi hakkında bilgi sahibi yapması & 6 & 7 & 13 \\
İnsanlara tarihi eksik öğretmesi & 4 & 2 & 6 \\
İnsanlara tarihi gerçekleri unutturması & 3 & 3 & 6 \\
İnsanları tarihi araştırmaya yönlendirmesi & 2 & 2 & 4 \\
Toplumsal yaşama etkisi yoktur & 3 & 1 & 4 \\
Milli duyguların gelişmesini sağlaması & 3 & 3 & 6 \\
İnsanların bazı dizi karakterlerinden etkilenmesi & 1 & 1 & 2 \\
Kılık-kıyafet olarak etkilemesi & 1 & 1 & 2 \\
Okullarda öğretilemeyenlerin medya yoluyla öğretilmesi & - & 1 & 1 \\
Genç nesil arasında Neo-Osmanlıcılık akımını başlatması & - & 1 & 1 \\
Çocukların isimlerinin dizi karakterinden konulması & - & 1 & 1 \\
Toplumsal algı oluşumunda etkili olması & - & 1 & 1 \\
İnsanları şiddete yöneltmesi & 1 & - & 1 \\
Toplam & 34 & 31 & 65 \\
\hline
\end{tabular}


Öğretmenler tarihi dizilerin toplumsal yaşama etkilerine ilişkin hem olumlu hem de olumsuz şekilde cevap vermişlerdir. Öğretmenler en fazla sırasıyla "İnsanların tarihe merakını/ilgisini artırması" ( $\mathrm{f}=16$, Kadın=9, Erkek=7); "İnsanları kendi tarihi hakkında bilgi sahibi yapması" ( $\mathrm{f}=13$, Kadın=6, Erkek=7); "İnsanlara tarihi eksik öğretmesi" (f=6, Kadın=4, Erkek=2) ve "İnsanlara tarihi gerçekleri unutturması" $(\mathrm{f}=5$, Kadın=3, Erkek=3) şeklinde görüşlerini belirtmektedirler. Hem kadın hem de erkek öğretmenler tarihi dizilerin en fazla "İnsanların tarihe merakını/ilgisini artırması" ile ilgili görüş belirtmişlerdir. Buna göre tarihi dizilerin toplumsal yaşama hem olumlu hem de olumsuz yansımalarının olduğu söylenebilir. Araştırmaya katılan öğretmenlerden bazıları araştırmanın bu sorusunu şöyle cevaplamışlardır:

ÖK-7: "İnsanların tarihe merak duygusunu güçlendiriyor."

ÖE-10: "İnsanlar çocuklarının isimlerini dizi karakterlerinden seçiyorlar."

ÖK-23: "Tarihe olan merakı arttırdığı bir gerçek."

ÖK-27: "Tarih bilincinin oluşmasında etkili oluyor."

ÖE-35: "Vatan ve millet sevgisinin artmasını sağlıyor."

ÖK-45: "Geçmişimizi iyi anlamamızı sağlıyor."

ÖE-53: "Bence toplumun titreyip kendine dönmesinde etkili. Geçmişte yaşanan olayların günümüzde farklı şekillerde teşekkül ettiğine dair farkındalık oluşturması bakımından etkili."

ÖK-59: "Bence en büyük etkisi, insanımızın şanlı bir tarihe sahip olduğunu görmesi, ecdadını daha iyi tanıma firsatı bulması, dizilerle yetinmeyip akademik kaynaklardan da doğruluğunu araştırma gereği hissettirmesidir."

Öğretmenler tarihi dizilerin toplumsal yaşama etkilerine yönelik somut örnekler vermektedirler. $\mathrm{Bu}$ örnekler hem olumlu hem de olumsuz yöndedir. Bu durum öğretmenlerin tarihi dizileri yönelik tutumları ile açıklanabilir.

\subsection{Sekizinci Alt Probleme İlişkin Bulgular}

Araştırmanın sekizinci alt problemi "Öğretmenlere göre tarihi dizilerde kendilerini rahatsız eden durumları nelerdir?” şeklindedir. Öğretmenlerin araştırmanın bu sorusuna ilişkin verdikleri cevaplara ilişkin bulgular Tablo 11'de yer almaktadır:

Tablo 11.

Tarihi dizilerde öğretmenleri rahatsız eden durumlara ilişkin betimsel veriler

\begin{tabular}{lccc}
\hline Görüşler & Kadın & Erkek & Toplam \\
\hline Kadın ve erkek özel ilişkilerinin ön planda tutulması & 11 & 6 & 15 \\
Tarihi gerçeklerin saptırılması & 8 & 4 & 12 \\
Çok fazla şiddet sahnesinin bulunması & 3 & 1 & 4 \\
Tarihi olaylara objektif bir yaklaşım sergilenmemesi & 2 & 2 & 4 \\
Siyasal ideolojiye göre tarihi olayların şekillendirilmesi & - & 3 & 3 \\
Dizilerin akıcılığında skıntılar bulunması & 2 & 1 & 3 \\
Kahramanların aşı̈ı yüceltilmesi & 2 & - & 2 \\
Tarihi olayların günümüz şartlarında yorumlanması & - & 1 & 1 \\
Tarihin dizilerle öğretilmeye çalışılması & 1 & - & 1 \\
Tarihi olayların dizilerde abartılı verilmesi & - & 1 & 1 \\
Gereksiz detaylara değinilmesi & - & 1 & 1 \\
Dizilerin çocuklar için uygun olmaması & 1 & - & 1 \\
Rahatsız edici bir durum yok & - & 1 & 1 \\
Toplam & 31 & 20 & 51 \\
\hline
\end{tabular}

Tablo 11'de tarihi dizilerde öğretmenleri rahatsız eden durumlar ele alınmaktadır. Buna göre öğretmenleri en çok rahatsız eden durumun "Kadın-erkek özel ilişkilerinin ön planda tutulması" ( $\mathrm{f}=15$, Kadın=11, Erkek=6) olduğu görülmektedir. Bunu "Tarihi gerçeklerin saptırılması" ( $\mathrm{f}=12, \mathrm{Kad} ı n=8$, Erkek=4); "Çok fazla şiddet sahnesinin bulunması" ( $\mathrm{f}=4$, Kadın=3, Erkek=1) ve "Tarihi olaylara objektif bir yaklaşım sergilenmemesi" ( $\mathrm{f}=4, \mathrm{Kad} ı n=2$, Erkek=2) görüşleri izlemektedir. Hem kadın hem de erkek öğretmenler en fazla "Kadın-erkek ilişkilerinin ön planda tutulması" (Kadın=11, Erkek=6) 
durumundan rahatsızlık duyduklarını belirtmektedirler. Araştırmaya katılan öğretmenlerden bazıları araştırmanın bu sorusunu şöyle cevaplamışlardır:

ÖE-4: "Osmanlı tarihini yansıtan dizilerin Avrupa merkezci bakış açısıyla harem hayatı temelli bir anlatıyı benimsemesi rahatsız edici."

ÖK-32: "Kadın erkek ilişkilerinin ön planda olması, özellikle kadının onurunun zedelenmesi."

ÖE-40: "Dizilerde hep Türk tarihindeki başarılar anlatılıyor. Sanki bu kişiler hiç savaş kaybetmedi. Bu objektifliğe zarar verir."

ÖK-47: "Tarihi dizileri takip eden kişilerin kurgu olan bölümleri gerçek zannetmesi."

ÖK-54: "Reyting için gerçek tarihe sadık kalınmıyor maalesef."

ÖK-36: "Kan ve şiddet normalleştiriliyor."

ÖE-61: "Gerçeklerden çok kurgu olması."

Öğretmenler izledikleri tarihi dizilerde rahatsız oldukları durumları çeşitli nedenlere dayandırmaktadırlar. Bu durum izledikleri tarihi diziye göre elbette farklılaşmaktadır. Ancak dizilerde tarihi gerçeklere sadık kalınmaması, kadın-erkek ilişkilerine odaklanılması, şiddete fazlaca yer verilmesi genel olarak rahatsızlık veren durumlar olarak yorumlanabilir.

\section{TARTIŞMA, SONUÇ ve ÖNERILER}

$\mathrm{Bu}$ araştırmada öğretmenler güncel tarihi dizilerden Diriliş Ertuğrul, Vatanım Sensin, Payitaht Abdülhamit, Mehmetçik Kut'ül Amare, Vikingler ve Aliya dizilerini izlediklerini belirtmişlerdir. Bu diziler içinde en fazla izledikleri dizi ise Diriliş Ertuğrul ve Vatanım Sensin dizileridir. Gezici ve Demir'in (2018) çalışmasında öğretmenler öğrencilerinin Diriliş Ertuğrul, Payitaht Abdülhamit ve Vatanım Sensin dizilerini izlediklerini belirtmişlerdir. Şahin'in (2019) çalışmasında öğretmen adaylarının Diriliş Ertuğrul dizisini izledikleri tespit edilmiştir. Buna göre literatürdeki çalışmalarda öğrencilerin ve öğretmenlerin izledikleri tarihi diziler ile bu araştırmada öğretmenlerin izledikleri tarihi dizilerin benzer diziler oldukları görülmektedir. Hem bu araştırmada hem literatürdeki çalışmalarda en popüler tarihi dizilerin Diriliş Ertuğrul, Vatanım Sensin ve Payitaht Abdülhamit dizileri olduğu görülmektedir.

Sosyal Bilgiler öğretmenleri geçmişte izledikleri tarihi dizileri Muhteşem Yüzyıl, Filinta ve Kuruluş "Osmancık" olarak belirtmişlerdir. Araştırmada Sosyal Bilgiler öğretmenleri Diriliş Ertuğrul dizisinin konusunu "Osmanlı'nın kuruluşu"; Vatanım Sensin dizisinin konusunu "Kurtuluş Savaşı"; Payitaht Abdülhamit dizisinin konusunu "Osmanlı tarihi" ve Mehmetçik Kut'ül Amare dizisinin konusu "I. Dünya Savaşı" olarak belirtmektedirler. Ayrıca öğretmenler yerli tarihi dizileri izledikleri gibi yabancı tarihi dizileri de takip etmişlerdir. Gezici ve Demir'in (2018) çalışmasında öğretmenler öğrencilerinin geçmişte Muhteşem Yüzyıl dizisini izlediklerini belirtmişlerdir. Özmen vd. (2014) da çalışmasında öğrencilerin, Kaya ve Günal'ın (2015) çalışmasında öğretmenlerin görüşleri doğrultusunda Muhteşem Yüzyıl dizisinin ele alındığı görülmektedir. Dolayısıyla geçmişte izlenen en popüler tarihi dizinin Muhteşem Yüzyıl olduğu söylenebilir. Bu durum bu araştırmadan elde edilen sonucu desteklemektedir. Öğretmenler izlemekte oldukları dizilerden daha çok Diriliş Ertuğrul (Ertuğrul, Artuk Bey, Bamsı Beyrek, Halime Hatun, Hayme Ana, Turgut Alp ve İbn'ül Arabi) ve Vatanım Sensin (Albay Cevdet, Hilal, Azize Hemşire, Hasibe Ana, Leon ve Sütçü Ramiz) tarihi dizi karakterlerinden etkilendiklerini belirtmektedirler. Öğretmenlerin en fazla etkilendikleri karakterin Diriliş Ertuğrul dizisi karakteri Ertuğrul, Vatanım Sensin dizisi karakteri Albay Cevdet ve Payitaht Abdülhamit dizisi karakteri II. Abdülhamit olduğu görülmektedir. Kadın öğretmenlerin en fazla etkilendiği dizi karakterleri Hilal, Ertuğrul ve Albay Cevdet karakterleri; erkek öğretmenlerin ise Ertuğrul, Bamsı Beyrek ve II. Abdülhamit karakterleridir. Öğretmenler karakterlerden etkilenme nedenlerini karakterlerin vatanmillet sevgisini ön planda tutmaları, Türk kadınına örnek olmaları ve cesur, akıllı, dürüst ve adil olmalarıdır. Kırtepe (2014) çalışmasında katılımcıların yarıya yakını düşük düzeyde dizi film karakterlerinden etkilendiklerini belirtmişlerdir. Yalçın (2016) çalışmasında popüler kültürün izleyicilere yaşam tarzı ve kimlik sunduğunu belirtmektedir. Diriliş Ertuğrul tarihi dizisinde de dizi karakterlerinin ön plana çıkardığı Türk kültürüne ait giyim tarzları (yerel kıyafetler), aile yaşamı, yönetim biçimi, inanç sistemi, konuşma biçimi ve davranış şekli izleyicileri etkilemektedir. Erjem ve 
Çağlayandereli'nin (2006) çalışmasında lise öğrencilerinin televizyon dizi karakterlerinden etkilendikleri tespit edilmiştir. Köse (2014) çalışmasında dizi karakterlerinin insanların çocuklarına verdikleri isimler aracılığıyla özel hayatımıza dâhil olduğundan bahsetmektedir. Ayrıca dizilerin insanlara model alabilecekleri kişilik modelleri sunduğunu da belirtir. Karakoç (2014) çalışmasında gençlik tarafından yerli ve yabancı dizi karakterlerinin model alınarak insanların özel hayatına müdahale edildiğini ifade etmektedir. Buna göre literatürde yapılan çalışmaların sonuçları ile bu araştırmadan elde edilen sonuçlar benzerlik göstermektedir.

Araştırmada öğretmenlerin çoğunluğu tarihi diziler ile tarihi gerçekler arasında fark olduğunu düşünmektedir. Bu öğretmenler tarihi dizilerin gerçek olaylar üzerine kurgulandığını ve reyting kaygısı ile gerçeklerin magazinsel sunulduğunu belirtmektedirler. Öğretmenlerden bazıları ise tarihi diziler ile tarihi gerçekler arasında fark olmadığını belirtmişlerdir. Bu öğretmenler ise tarihi dizilerde tarihi olayların doğrudan ve tarihi gerçekliğe uygun olarak aktarıldığını düşünmektedirler. Kaya ve Günal (2015) çalışmasında tarihi diziler çekilirken dönemin şartlarının yansıtılmasına dikkat edilmesi gerektiğini belirtirler. Erman (2016) çalışmasında tarihi dizilerin dönemin savunduğu politika doğrultusunda şekillendirildiğini ve bu şekilde kitlelerin yönlendirilmek istendiğini belirtilir. Ayrıca çalışmasında Filinta ve Diriliş Ertuğrul dizilerinde iktidarın savunduğu siyasi duruşun propagandasının yapıldığını tespit etmiştir. Dolayısıyla dizilerde tarihi gerçeklerin farklılaştırıldığına atıfta bulunulur. $\mathrm{Bu}$ çalışmaların sonuçları bu araştırmada tarihi dizilerin tarihi gerçeklerle farklılık göstermediğini savunan öğretmenlerin görüşleri ile çelişmektedir.

Araştırmada öğretmenler derslerinde tarihi dizilerle ilgili o dönemin yaşam tarzları, töre ve kurultayı, kılık-kıyafeti ve tarihi olayları örnek verdiklerini belirtmişlerdir. Adalı-Aydın (2016) çalışmasında Muhteşem Yüzyıl tarihi dizisinin yayınlandığı dönemde kıyafetlerinin, çağa ait söylemlerinin, saray ve sultanlık gibi konuların dikkat çekiciliği üzerinde durmaktadır. Kaya ve Günal'ın (2015) çalışmasında öğretmenler Muhteşem Yüzyıl dizisindeki divan-1 hümayun toplantılarını, kafes usulünü, hilat giydirmeyi örnek olarak verdiklerini belirtmişlerdir. Barton ve Levstik (2004) derslerde tarihi dizilerden faydalanılmasının konuyu somutlaştırması açısından önemli bulmaktadırlar. Çalışmalar bu yönüyle bu araştırmadan elde edilen sonucu desteklemektedir. Buna göre öğretmenlerin tarihi dizilerdeki bazı olay ve durumları derslerinde örnek olarak kullanabilecekleri söylenebilir.

Araştırmada öğretmenler tarihi dizilerin toplumsal yaşama etkilerine hem olumlu hem de olumsuz şekilde cevap vermişlerdir. Olumlu cevap veren öğretmenler insanların tarihe merakını/ilgisini artırması ve insanları kendi tarihi hakkında bilgi sahibi yapması; olumsuz cevap veren öğretmenler ise insanlara tarihi eksik öğretmesi ve insanlara tarihi gerçekleri unutturması şeklinde görüşlerini belirtmektedirler Öztaş vd. (2013) çalışmasında tarihi dizilerin tarihe ilgiyi artırdığını tespit etmiştir. Aktekin ve Çoban (2011) çalışmasında öğretmenler tarihi dizilerin öğrencilerinin tarih dersine ilgilerini artırdığını tespit etmişlerdir. Şahin (2019) çalışmasında tarihi dizileri izleyen öğretmen adaylarının tarih şuurunun güçlendiği sonucuna ulaşmıştır. Erman (2016) çalışmasında insanların tarihe dizilere ilgilerinin sadece farklı yaşam tarzları ve egzotik mekânlardan kaynaklanmadığını kültürel ve tarihi bağların da tarihi dizileri izlemeye yönelttiğini belirtir. Kaya ve Günal (2015) çalışmasında Muhteşem Yüzyıl dizisinin toplumun tarihe ilgisini artırdığını ve bazı kavramların öğrenilmesine katkı sağladığını belirtirken aynı zamanda dizinin harem entrikalarına odaklanması ve reyting kaygısının ön plana çıkmasını eleştirmektedirler. Bilis (2013) çalışmasında Muhteşem Yüzyıl dizisini ele almış, dizide yer alan müstehcen sahnelerin tarihi gerçekliği çarpıtmaktan ziyade dizinin popüler televizyon diline uygun hareket etme isteğinden kaynaklandığını belirtmektedir. Özmen vd. (2014) çalışmasında öğrenciler Muhteşem Yüzyıl dizisinde Osmanlı Devleti'nin ve Kanuni Sultan Süleyman'ın iyi yansıtılmadığını düşünmektedirler. Ocak ve Selimoğlu (2016) çalışmasında tarihi dizilerde karakterlerin ve olayların gerçeklerden uzaklaştırıldığını belirtirler. Literatürde yapılan çalışmalarda bu araştırmada olduğu gibi tarihi dizilerin toplumsal yaşama etkisi ile ilgili hem olumlu hem de olumsuz sonuçlar elde edilmiştir. Tarihi dizilerde öğretmenleri rahatsız eden durumlar kadın-erkek ilişkilerinin ön planda tutulması, tarihi gerçeklerin saptırılması, şiddet sahnelerinin bulunması ve tarihi olaylara objektif bir yaklaşım sergilenmemesidir. Bilis (2013) çalışmasında Muhteşem Yüzyıl dizisi örneğinden yola çıkarak dizide karakterler arasında bulunan ilişkilerin ve haremde yaşanan olayların gayri resmi tarih anlayışı içinde ele alındığııı belirtir. Kaya ve Günal'ın (2015) çalışmasında öğretmenler Muhteşem Yüzyıl dizisinin sadece harem odaklı bir dizi olmasını eleştirmektedirler. Dizilerde olay örgüsünün kurulmasında ve dizilerin devamının sağlanmasında aşk ilişkilerine, gerilime, çatışmaya ve şiddete sıklıkla yer 
verilmektedir (Geçer, 2015). Tarihi dizilerde gösterilen müstehcen sahneler ile şiddet içeren sahneler (kavga, savaş, hakaret vb.) toplumsal değerlere zarar vermektedir (Kaya ve Çengelci, 2011).

$\mathrm{Bu}$ araştırmanın sonuçlarından yola çıkılarak şu öneriler ileri sürülebilir:

Araştırmada öğretmenler tarihi dizilerin olumsuz özelliklerine değinmişlerdir. Dizilerde gösterilen müstehcen ve şiddet içeren sahneleri çocuklar da izlemektedir. Dizi yapımcıları ve senaristlerin bu durumu düşünerek hareket etmeleri gerekmektedir. Ayrıca tarihi olay ve karakterlerin gerçeğe uygun bir şekilde sunulması için akademik kaynaklar referans olarak kullanılabilir. İlgili konuda çalışan akademisyenlerden yardım istenebilir.

Milli Eğitim Bakanlığı tarafindan her yıl öğretmen ve öğrencilerin izleyebileceği uygun diziler önerilebilir. Böylece öğretmenler derslerinde yararlanabilecekleri dizileri kolaylıkla seçebilir ve öğrencilerine önerebilirler. Okullarda Sosyal Bilgiler derslerinde kullanılmak üzere tarihi dizi arşivleri oluşturulabilir.

\section{KAYNAKÇA}

Adalı-Aydın, G. (2016). Reklamlar ve diziler bağlamında bir popüler kültür incelemesi: Muhteşem Yüzyıl Dizisinin reklam metinlerine etkisi. Global Media Journal TR Edition, 7(13), 137-150.

Aktekin, S. ve Çoban, Z. (2011). Tarih derslerinde tarihi film ve dizilerin kullanımına ilişkin öğretmen ve öğrenci görüssleri: Trabzon örneği. Karadeniz İncelemeleri Dergisi, 13, 141-160.

Altınbaş-Sarıül, F. (2017). Popüler kültürün dolaşıma sokulmasında televizyon dizilerinin rolünün baudrillard ekseninde değerlendirilmesi. Proceedings of INTCESS 2017 4th International Conference on Education and Social Sciences, İstanbul, Türkiye.

Barton, K. C. \& Levstik, L. S. (2004).Teaching history for the common good. Mahwah, NJ: Lawrence Erlbaum Associates.

Bilis, A. E. (2013). Popüler televizyon dizilerinden Muhteşem Yüzyıl dizisi örneğinde tarihin yapısökümü. İstanbul Üniversitesi İletişim Fakültesi Dergisi, II (45), 19-38.

Büyüköztürk, Ş., Kılıç Çakmak, E., Akgün, Ö. E. \& Demirel, F. (2012). Bilimsel araştırma yöntemleri. Ankara: Pegem Akademi Yayıncılık.

Cengiz, E. (2010). Popüler kültür ve sanat. Folklor/Edebiyat, 16(64), 7-14.

Cohen, L., Manion, L., \& Morrison, K. (2007). Research methods in education. New York, NY, US: Routledge/Taylor \& Francis Group.

Coşgun, M. (2012). Popüler kültür ve tüketim toplumu. Batman Üniversitesi Yaşam Bilimleri Dergisi, $1(1), 837-850$.

Erdoğan, İ. \& Alemdar, K. (2005). Popüler kültür ve iletişim. Ankara: Erk Yayınları.

Erjem, Y. \& Çağlayandereli, M. (2006). Televizyon ve gençlik: yerli dizilerin gençlerin model alma davranışı üzerindeki etkisi. C.Ü. Sosyal Bilimler Dergisi, 30(1), 15-30.

Ekiz, D. (2013). Bilimsel araştırma yöntemleri. Ankara: Anı Yayıncılık.

Erman, S. (2016). Bir propaganda aracı olarak tarihi diziler: "Diriliş Ertuğrul" ve "Filinta" örneği. Yüksek Lisans Tezi, Marmara Üniversitesi Sosyal Bilimler Enstitüsü, İstanbul.

Geçer, E. (2015). Türk dizileri üzerine ideolojik ve kültürel bir değerlendirme: "Made in Turkey". Mütefekkir, 2(3), 13-23.

Gezici, M. \& Demir, S. B. (2018). Tarihi dizi ve filmlerin Sosyal Bilgiler dersine yansımaları. Turkish History Education Journal, 7(2), 392-413.

Giddens, A. (2005). Sosyoloji. Cemal Güzel (Haz.), Ankara: Ayraç Yayınevi.

Güllüoğlu, Ö. (2012). Bir kitle iletişim aracı olarak televizyonun popüler kültür ürünlerini benimsetme ve yayma işlevi üzerine bir değerlendirme. Global Media Journal, 2(4), 64-86.

Kalçık, C. (2017). Tarihi dizilerde yaşam boyu ögrenme algısı (Bartın ili örneği). Yüksek Lisans Tezi, Bartın Üniversitesi Eğitim Bilimleri Enstitüsü, Bartın.

Kalçık, C. (2019). Tarihi dizilerle yaşamboyu öğrenme algısının televizyon izlenme durumuna göre incelenmesi. Erzincan Üniversitesi Eğitim Fakültesi Dergisi, 21(1), 113-134. 
Karakoç, E. (2014). Medya aracılı̆̆ıyla popüler kültürün aktarılmasında toplumsal değişkenlerin rolü. Gümüşhane Üniversitesi İletişim Fakültesi Dergisi, 2(3), 245-269.

Kaya, E. \& Çengelci, T. (2011). Öğretmen adaylarının sosyal bilgiler eğitiminde filmlerden yararlanılmasına ilişskin görüşleri. Sosyal Bilgiler Eğitimi Araştırmaları Dergisi, 2(1), 116-135.

Kaya, R. \& Günal, H. (2015). Tarih öğretmenlerinin Muhteşem Yüzy1l dizisi özelinde tarih konulu film ve dizilerin öğretimde kullanımına yönelik görüşleri. Turkish History Education Journal, 4(1), $1-48$.

Kırtepe, S. (2014). Televizyon dizilerinin toplum üzerindeki etkileri sosyokültürel bir çözümleme (Erzurum Örneği), Yayımlanmamış Doktora Tezi, Atatürk Üniversitesi Sosyal Bilimler Enstitüsü, Erzurum.

Kızıldağ, Ş. (2001). Pop müzikten popüler kültüre medya çocukları. İstanbul: Şehir Yayınları.

Köse, A. (2014 ). Değişimin gölgesindeki gelenek: popüler diziler ve farklılaşan ad verme kültürü. Milli Folklor, 101, 291-306.

Ocak, G. \& Selimoğlu, S. (2016). Tarih öğretiminde tarih dizilerinin kullanımına ilişkin öğrenci görüşleri: Nitel bir analiz. Kastamonu Eğitim Dergisi, 24(1), 431-452.

Özmen, C., Er, H. \& Ünal, F. (2014). Televizyon dizilerinin tarih bilinci üzerine etkisi: "Muhteşem Yüzy1l" dizisi örneği. Mustafa Kemal Üniversitesi Sosyal Bilimler Enstitüsü Dergisi, 11(25), 409-426.

Öztaş, S. (2007). Tarih ögrretimi ve filmler: tarih ögrretiminde film kullanılmasının öğrenci başarı üzerindeki etkisi. Doktora Tezi., Gazi Üniversitesi Eğitim Bilimleri Enstitüsü, Ankara.

Öztaş, S., Anıl, N. K. \& Kılıç, B. (2013). Tarihî film veya tarihî dizilerin tarihe ilgiyi artırmada etkisine ilişkin myo öğrencilerinin görüşleri. Electronic Journal of Vocational Colleges, UMYOS Özel Sayl, 107-120.

Öztaş, S. (2015). Tarih öğretiminde tarihî film ve tarihî dizilerin kullanılmasına ilişkin tarih bölümü öğrencilerinin görüşleri. Turkish History Education Journal, 4(2), 1-37.

Patton, M. Q. (2014). Nitel araştırma ve değerlendirme yöntemleri. Mesut Bütün, Selçuk Beşir Demir (Çev. Ed.), Ankara: Pegem Akademi Yayıncılık.

Rosenstone, R. A. (2001). The historical film: Looking at the past in a postliterate age. In A. Marcia Landy (Eds.), The Historical Film: History and Memory in Media (50-66). New Brunswick,New Jersey : Rutgers University Press.

Sakallı, E. (2014). Türkçe popüler kültür. Uluslararası Türkçe Edebiyat Kültür Eğitim Dergisi, 3(2), 307-317.

Şahin, K. (2019). Öğretmen adaylarının tarihi dizi/filmlerle yaşam boyu ögrenme algısı ve tarih şuuru oluşumu hakkındaki görüşlerinin belirlenmesi. Yüksek Lisans Tezi, Erzincan Binali Yıldırım Üniversitesi Sosyal Bilimler Enstitüsü, Erzincan.

Tezcan, M. (2000). Sosyo-kültürel değişim sürecinde Türkiye'de gençlik, Türkiye'de ve Avrupa'da gençlik. Ankara: Türk Demokrasi Vakfı (Konrad - Adenauer- Vakfi).

Turner, T. (1979). Using popular culture in the social studies. http://www.eric.ed.gov/. (Erişim tarihi: $30.09 .2019)$

Yaktıl-Oğuz, G. (2005). TV dizileri ve kültürel iletilerin yayılma süreci. Kurgu Dergisi, 21, 169-182.

Yalçın, M. (2016). Popüler kültür ürünü olarak türk televizyon dizilerinde etnografik iletişim kodların kullanımı: "Diriliş Ertuğrul" dizisi örneği. İnsan ve Toplum Bilimleri Araştırmaları Dergisi, 5(7), 2332-2341.

Yaylagül, L. (2004). Yarışma programları ve ideolojisi. Bilim ve Aklın Aydınlı̆̆ında Eğitim, 57, 180188.

Yin. R. K. (1984). Case study researcg: Design and methods. Beverly Hilss, CA:Sage.

Yıldırım,A. \& Şimşek, H. (2016). Sosyal bilimlerde nitel araştırma yöntemleri. Ankara: Seçkin Yayıncilik. 
Yücel, A. (2019). "Muhteşem Yüzyll” dizisinin alımlama analizi: Kadın ve erkek imajı üzerine farklı okumalar. 1-33. http://www.sdergi.hacettepe.edu.tr/makaleler/muhtesemyuzyil.pdf (Erişim tairhi: 30.09.2019). 